\title{
Fusarium graminearum arabinanase (Arb93B) Enhances Wheat Head Blight Susceptibility by Suppressing Plant Immunity
}

\author{
Guixia Hao, ${ }^{+}$Susan McCormick, Martha M. Vaughan, Todd A. Naumann, Hye-Seon Kim, Robert Proctor, \\ Amy Kelly, and Todd J. Ward \\ Mycotoxin Prevention and Applied Microbiology Research Unit, National Center for Agricultural Utilization Research, United \\ States Department of Agriculture-Agricultural Research Service, Peoria, IL, U.S.A.
}

Accepted 11 February 2019.

\begin{abstract}
Fusarium head blight (FHB) of wheat and barley caused by the fungus Fusarium graminearum reduces crop yield and contaminates grain with mycotoxins. In this study, we investigated two exo-1,5- $\alpha$-L-arabinanases (Arb93A and Arb93B) secreted by $F$. graminearum and their effect on wheat head blight development. Arabinan is an important component of plant cell walls but it was not known whether these arabinanases play a role in FHB. Both $A R B 93 A$ and $A R B 93 B$ were induced during the early stages of infection. arb93A mutants did not exhibit a detectable change in ability to cause FHB, whereas arb93B mutants caused lower levels of FHB symptoms and deoxynivalenol contamination compared with the wild type. Furthermore, virulence and deoxynivalenol contamination were restored to wild-type levels in $A R B 93 B$ complemented mutants. Fusion proteins of green fluorescent protein (GFP) with the predicted chloroplast peptide or the mature protein of Arb93B were not observed in the chloroplast. Reactive oxygen species (ROS) production was reduced in the infiltrated zones of Nicotiana benthamiana leaves expressing ARB93B-GFP. Coexpression of $A R B 93 B-G F P$ and Bax in N. benthamiana leaves significantly suppressed Bax-programmed cell death. Our results indicate that Arb93B enhances plant disease susceptibility by suppressing ROS-associated plant defense responses.
\end{abstract}

Keywords: deoxynivalenol, exo- $\alpha-\mathrm{L}$-arabinanase, fungal effectors, fungus-plant interactions, Fusarium head blight, gene expression, mutagenesis, plant immunity

Plants have a highly complex immune response to microbial infection, and characterization of the various components of the response is crucial to understand plant immune

Mention of trade names or commercial products in this publication is solely for the purpose of providing specific information and does not imply recommendation or endorsement by the U.S. Department of Agriculture. USDA is an equal opportunity provider and employer.

${ }^{\dagger}$ Corresponding author: G. Hao; guixia.hao@ars.usda.gov

*The $\boldsymbol{e}$-Xtra logo stands for "electronic extra" and indicates that one supplementary table and four supplementary figures are published online.

The author(s) declare no conflict of interest.

(c) 2019 The American Phytopathological Society systems and to improve plant disease resistance. The pathogen-associated molecular patterns (PAMPs) such as bacterial flagellin and fungal chitin can bind pattern recognition receptors (PRRs) and activate PAMP-triggered immunity (PTI). PTI results in calcium ion $\left(\mathrm{Ca}^{2+}\right)$ influx, reactive oxygen species (ROS) burst, callose deposition, and defense gene activation (Gómez-Gómez et al. 2001). PTI is effective in preventing infection by most potential pathogens; however, successful pathogens secrete effectors to overcome PTI and to suppress host defenses. Effectors interfere with plant immunity by inhibiting perception of plant PRRs, downregulating mitogen-activated protein kinase (MAPK) signaling, and degrading defense proteins (Göhre and Robatzek 2008). Recognition of these effectors by plant resistant proteins can activate effector-triggered immunity (ETI) (Jones and Dangl 2006). ETI is associated with programmed cell death (PCD), also called hypersensitive response. ROS generated by the plasma membrane NADPH oxidases as well as plant organelles, including the chloroplast and mitochondria, is essential for PTI and ETI (Coll et al. 2011). Screening of pathogen effectors capable of suppressing ROS or PCD has been performed in tobacco and Arabidopsis to aid in characterization of their function (Abramovitch et al. 2003; Dou et al. 2008; Ramachandran et al. 2017; Q. Wang et al. 2011). The expression of proapoptotic mouse protein Bax, a member of the of the Bcl-2 protein family, leads to ROS generation, and ROS accumulation disrupts plant plasma membranes which, in turn, results in PCD (Kawai-Yamada et al. 2004; Lacomme and Santa Cruz 1999). The Bax-induced PCD assay provides a useful tool for screening effectors. Numerous effectors from bacteria, fungi, and oomycetes were demonstrated to suppress PTI, ETI, or both (Guo et al. 2009; Jamir et al. 2004; Ramachandran et al. 2017; Q. Wang et al. 2011).

The hemibiotrophic plant pathogen Fusarium graminearum is the main causal agent of Fusarium head blight (FHB) in wheat and barley. This disease not only reduces crop yields but also causes grain contamination with trichothecene mycotoxins, including deoxynivalenol (DON) and nivalenol. Consumption of trichothecene-contaminated grain threatens the health and wellbeing of humans and animals (Desjardins and Hohn 1997). DON is also a major virulence factor necessary for disease spread after initial infection in some hosts, including wheat (Bai et al. 2002; Proctor et al. 1995). Mutagenesis experiments have identified a number of genes whose deletion results in altered toxin biosynthesis, mycelia growth, conidia germination, sporulation, or protein kinase signaling, which can 
subsequently influence pathogenesis and mycotoxin contamination of grain (Son et al. 2011; C. Wang et al. 2011). However, the importance of FHB and an inability to adequately control this disease have spurred significant interest in the identification of additional virulence factors in $F$. graminearum.

Many phytopathogenic fungi secrete an array of plant cellwall-degrading enzymes (CWDEs) to break down the cell wall, initiate infection, and obtain nutrition. There is evidence that several extracellular fungal CWDEs such as polygalacturonases, pectate lyases, xylanases, and lipases are involved in virulence and host-pathogen interactions. For example, inactivation of the $F$. graminearum-secreted lipase gene FGL1 results in reduced FHB development (Voigt et al. 2005). A xylanase encoded by the gene FG_03624 induced necrosis in wheat tissues but it did not affect disease development (Sella et al. 2013). However, $F$. graminearum double mutants in which both a xylanase and an endo-polygalacturonase gene have been disrupted cause less disease in wheat and soybean (Paccanaro et al. 2017). A secretome study of $F$. graminearum predicted 94 secreted CWDEs targeting the plant cell wall, with 46 of them predicted to be involved in hemicellulose degradation (Brown et al. 2012).

Arabinan is one of the most abundant side chains in plant cell wall hemicellulose and pectin. For example, wheat bran contains 19\% xylan and 15\% arabinan (Hayn et al. 1993). To complete degradation of hemicellulose and pectin, arabinanases act synergistically with other glycoside hydrolases (GHs) (Margolles-Clark et al. 1996). Endo-arabinanases cut randomly in the backbone of the arabinan, whereas exo-acting $\alpha$-Larabinofuranosidases release terminal nonreducing $\alpha-\mathrm{L}$ arabinofuranoside residues from different $\alpha$-L-arabinosides, arabinans, arabinoxylans, and arabinogalactans (Seiboth and Metz 2011). $\alpha$-L-arabinanases are classified into families based on their substrate specificities (Beldman et al. 1997). For example, the GH51 and GH54 arabinanase families include primarily $\alpha$-L-arabinofuranosidases that remove $\alpha-1,2$ and $\alpha-1,3$ arabinofuranosyl moieties from arabinan and arabinoxylans (Paës e al. 2008), while the GH93 family includes exo-1,5- $\alpha-\mathrm{L}-$ arabinanases that release terminal arabinose or short arabinooligosaccharides from arabinan. GH93 exo-1,5- $\alpha$-L-arabinanases share the six-bladed $\beta$-propeller structure found in sialidases, a group of enzymes that remove terminal sialic acid from glycoconjugates. Several sialidases are associated with bacterial pathogenesis. In Pseudomonas aeruginosa, a sialidase was found to facilitate bacterial infection by causing biofilm formation (Soong et al. 2006). Sialidases can convert gangliosides to the cholera toxin receptor $\mathrm{GM}_{1}$, and promote the cholera toxin binding to the host cell receptor in the bacterial pathogen Vibrio cholerae (Galen et al. 1992). Streptococcus pneumoniae can obtain carbohydrates from host glycoproteins for growth using two sialidases (Burnaugh et al. 2007). Although the important roles of sialidases have been demonstrated during pathogenesis, the roles of arabinanases in microbial pathogenesis are less defined. Nevertheless, the endo-arabinanase BcAra1 from the fungus Botrytis cinerea is a host-specific virulence factor and a key determinant of disease on Arabidopsis (Nafisi et al. 2014), and arabinofuranosidase are required for wild-type virulence of the fungus Sclerotinia trifoliorum on winter pea stems (Rehnstrom et al. 1994).

During the interaction of $F$. graminearum and wheat coleoptile, the expression of 16 arabinanases (from families GH43, GH51, GH54, and GH62) increased dramatically (Zhang et al. 2012). However, the two exo-1,5- $\alpha$-L-arabinanases, Arb93A and Arb93B, were not among the 16 arabinanases examined; thus, it is not known whether these enzymes play a role in FHB (Carapito et al. 2009). Arb93A has a strict substrate specificity for linear $\alpha-1,5-\mathrm{L}$-arabinan and releases arabinobiose from the nonreducing end (Carapito et al. 2009). In a preliminary analysis, we identified a chloroplast-targeting peptide in Arb93B located after the N-terminal signal peptide. Several previous studies have shown that effectors targeting chloroplasts can play a major role in plant-pathogen interactions. For example, the $P$. syringae effector Hop1 can bind the plant heat shock protein Hsp70, recruit cytosolic Hsp70 to chloroplasts, remodel host chloroplasts, and suppress plant defense (Jelenska et al. 2007, 2010). Given the role that some arabinanases and chloroplast-targeted effectors can play in plant disease, we investigated whether Arb93A and Arb93B affect pathogenesis of $F$. graminearum on wheat. Initially, we examined the expression of $A R B 93 A$ and $A R B 93 B$ during $F$. graminearum infection of wheat heads, and then evaluated pathogenicity of $A R B 93 A$ and $A R B 93 B$ deletion mutants. To determine the potential mechanism by which Arb93B affects wheat head blight development, we also examined the localization of Arb93B, ROS production, and cell death suppression via transient expression of Arb93B in Nicotiana benthamiana.

\section{RESULTS}

\section{Nucleotide and amino acid sequences of Arb93A and Arb93B.}

Arb93A is encoded by locus FGSG_03054 residing on chromosome 2 of $F$. graminearum strain $\mathrm{PH}-1$. The nucleotide sequence of the corresponding gene, $A R B 93 A$, contains an intron at the 491-nucleotide location and encodes 380 amino acids (aa), with a 16-aa signal peptide predicted by SignalP4.1 (Fig. 1). Arb93A exhibited a strict substrate specificity for linear $\alpha-1,5-\mathrm{L}-$ arabinan and a canonical six-bladed $\beta$-propeller structure (Carapito et al. 2009). Arb93B is encoded by locus FGSG_03598 locating on chromosome 2, approximately $1.46 \mathrm{Mb}$ from $A R B 93 A$. ARB 93B does not include an intron and encodes a 390aa protein. Arb93B contains a 19-aa signal peptide predicted by SignalP4.1. Arb93A and Arb93B share 52\% amino acid sequence identity, including several amino acids (Asp170, Asp242, and Tyr337) that are essential for wild-type arabinanase activity (Carapito et al. 2009). The putative mature Arb93B protein was predicted by the I-TASSR program (Zhang et al. 2008) as a canonical six-bladed $\beta$-propeller structure similar to Arb93A. These two exo- $\alpha$-L-arabinanases in $F$. graminearum were suggested to share a similar function but with different substrate specificities (Carapito et al. 2009). Interestingly, the ChloroP program predicted that Arb93B contains a chloroplast-targeting peptide that is absent in Arb93A (Fig. 1; Supplementary Fig. S1). We hypothesized that Arb93B is localized in the plant chloroplast and functions as an effector in countering plant immunity and promoting $F$. graminearum pathogenesis.

\section{Induction of $A R B 93 A$ and $A R B 93 B$ in infected wheat head tissue.}

To determine whether $A R B 93 A$ and $A R B 93 B$ were induced during pathogenesis, we inoculated susceptible spring wheat variety Norm at midanthesis by dipping the heads in a spore suspension. The expression levels of $A R B 93 A$ and $A R B 93 B$ were determined at various time points after whole head

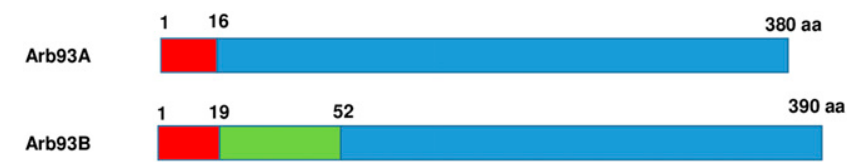

Fig. 1. Protein domain organization of the Fusarium graminearum Arb93A and Arb93B. Left box indicates the predicted secretion signal peptide and middle box (lower level) indicates the predicted chloroplast targeting peptide. Numbers indicate amino-acid (aa) position from N-terminus. 
inoculation. Gene expression studies revealed that ARB93A transcripts were induced 50 -fold as early as 1 day postinoculation (dpi), then gradually declined till $4 \mathrm{dpi}$, and stayed at the same level from 4 to $7 \mathrm{dpi}$ (Fig. 2). The transcripts of $A R B 93 B$ were detected at $1 \mathrm{dpi}$, peaked at $3 \mathrm{dpi}$, and were maintained at the same level from 4 to $7 \mathrm{dpi}$ (Fig. 2). Our results demonstrated that both $A R B 93 A$ and $A R B 93 B$ were upregulated in the early stages of $F$. graminearum infection.

\section{Generation of $A r b 93 A$ and $A r b 93 B$ deletion mutants.}

The induction of $A R B 93 A$ and $A R B 93 B$ expression in wheat tissue indicated that the genes might contribute to the ability of $F$. graminearum to colonize or infect wheat heads. Therefore, we created $A R B 93 A$ and $A R B 93 B$ deletion mutants (designate $a r b 93 A$ and $a r b 93 B$ ) by replacing the coding region of each gene with the hygromycin resistance gene, $h y g B$. To delete $A R B 93 A$, we used an Agrobacterium-mediated transformation protocol and macroconidia of the wild-type progenitor strain PH-1. Following the protocol, eight hygromycin-resistant transformants were selected for polymerase chain reaction (PCR) analysis. In this analysis, a 1,140-bp fragment corresponding to the $A R B 93 A$ coding sequence was amplified from the wild-type progenitor but not from the seven transformants. In contrast, PCR products were amplified from the transformants using primers located up- and downstream of the deletion construct (primers Arb93A-attb2r and Arb93A-attb3). Sequence analysis of the latter products confirmed the presence of hygB.

We used a protoplast-mediated transformation protocol combined with split-marker deletion constructs to delete $A R B 93 B$. Following the protocol, we selected 12 hygromycinresistant transformants for PCR analysis. The absence of the target gene was confirmed in three mutants (arb93B-M4, -M10, and -M11) by PCR amplification (Supplementary Fig. S2). The presence of $h y g B$ was confirmed in these mutants by primers located outside of target gene $A R B 93 B$. Furthermore, wholegenome sequence analysis of three mutants $\operatorname{arb} 93 A-\mathrm{M} 1,-\mathrm{M} 2$, and $a r b 93 B-M 10$ confirmed deletion of the target coding region of each gene and the replacement with hyg $B$. The genome sequence analysis also indicated that none of the mutants had an ectopic insertion of $h y g B$.

There were no obvious differences in growth or morphology between the wild type and the $a r b 93 A$ and $a r b 93 B$ deletion

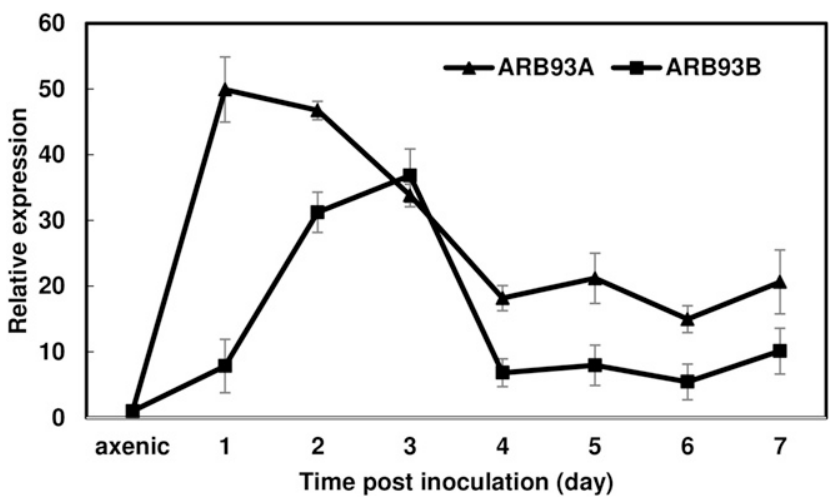

Fig. 2. Relative expression level of $A R B 93 A$ and $A R B 93 B$ during wheat head infection. Samples were prepared from wheat heads collected 1, 2, 3, $4,5,6$, and 7 days after dip inoculation. Six heads were collected at each time point and two heads were combined as one sample for RNA isolation and cDNA synthesis. Gene expression was determined by reverse-transcription quantitative polymerase chain reaction. Fungal $\beta$-tubulin was used as internal control for transcript normalization. Fold changes of gene expression were relative to Fusarium graminearum $\mathrm{PH}-1$ axenic culture, which were grown on V8 plate for seven days. mutants. In addition, gas chromatography-mass spectrometry (GC-MS) analysis showed that 15-acetyl-deoxynivalenol (15ADON) production was similar in the wild type and $\operatorname{arb} 93 \mathrm{~A}$ and $a r b 93 B$ deletion mutants.

\section{$A R B 93 B$ deletion reduces virulence.}

To determine whether $A R B 93 A$ and $A R B 93 B$ contribute to virulence toward wheat, $\mathrm{PH}-1$ and mutants $\operatorname{arb} 93 A-\mathrm{M} 1$, arb93A-M2, $a r b 93 B-\mathrm{M} 10$, and $a r b 93 B-\mathrm{M} 11$ were tested on the susceptible spring wheat Norm. To assess FHB development, bleaching and necrosis symptoms of spikelets were monitored at $7,10,14,17$, and $21 \mathrm{dpi}$. By $21 \mathrm{dpi}$, the majority of heads inoculated with PH-1 were completely bleached. Wheat heads inoculated with arb93A mutants showed FHB progression similar to those inoculated with PH-1 (Supplementary Fig. S3). In contrast, the majority of spikelets on the wheat heads inoculated with mutant $a r b 93 B-M 10$ or -M11 were asymptomatic (Fig. 3). Statistical analyses confirmed that the severity of FHB symptoms was significantly reduced following inoculation with arb $93 B$ mutants compared with PH-1 (Fig. 4A). Wheat heads were harvested at $21 \mathrm{dpi}$ to determine their weight and for analysis of trichothecene contamination. Heads inoculated with arb93B mutants had significantly greater biomass than those inoculated with PH-1 (Fig. 4B). GC-MS analyses revealed that heads inoculated with $a r b 93 B$ mutants had $80 \%$ less DON than PH-1-inoculated wheat heads (Fig. 4C).

To verify that the observed reduction in disease and DON contamination caused by the $\operatorname{arb} 93 B$ mutants was due to the lack of a functional ARB93B and not simply an artifact of the transformation process, $A R B 93 B$-complemented mutants were generated by Agrobacterium-mediated transformation using geneticin as a selectable marker. Following isolation of geneticin-resistant transformants from single conidia, the presence of $A R B 93 B$ was confirmed by PCR analysis. Wheat florets at midanthesis were point inoculated with wild-type $\mathrm{PH}$ 1 or $A R B 93 B$-complemented mutant $A R B 93 B-\mathrm{CP} 1$ or $\mathrm{CP} 2$ strains. At $21 \mathrm{dpi}$, the severity of symptoms caused by $A R B 93 B$ complemented mutants ( 85 to $95 \%$ ) was not significantly different from PH-1 (Fig. 5A). The head weight and DON levels in wheat inoculated with the complemented mutants were comparable with those inoculated with the wild-type strain $\mathrm{PH}-1$ (Fig. 5). These results confirmed that $A R B 93 B$ deletion was responsible for reduced $\mathrm{FHB}$ and DON contamination in wheat. Taken together, our findings indicate that $A R B 93 B$ contributes to the pathogenicity of $F$. graminearum on wheat.

\section{Localization of Arb93B in tobacco.}

Because Arb93B was predicted by ChloroP to contain a chloroplast localization peptide, the localization of Arb93B was examined using an Arb93B-green fluorescent protein (GFP) fusion protein. Initially, we generated a construct encoding GFP fused to the mature Arb93B protein, including the predicted chloroplast localization peptide. Introduction of the fusion construct into $N$. benthamiana using an Agrobacterium-mediated transient expression and leaf infiltration system resulted in accumulation of the Arb93B-GFP fusion protein in the cytoplasm and nucleus in infiltrated leaves. However, this result was not different from the result with the GFP control (data not shown). We suspected that improper folding of the Arb93B-GFP fusion protein might have affected its localization. Therefore, we generated a second construct encoding the predicted chloroplast localization peptide alone fused with GFP (designated GFP-Arb93BC). However, infiltration of $N$. benthamiana leaves resulted in accumulation of the GFP-Arb93BC in the cytoplasm and nucleus. Additionally, we noticed that GFP-Arb93BC fusion proteins resulted in stronger signals in the cell membrane area than the GFP control 
(Supplementary Fig. S4). Despite the ChloroP prediction (0.95) that Arb93B would be targeted to the chloroplast, our results suggest that Arb93B is localized in the cytoplasm and nucleus via transient expression in $N$. benthamiana.

\section{Suppression of plant immunity by Arb93B.}

To determine whether Arb93B functions as an effector to trigger or suppress plant immunity, we infiltrated $N$. benthamiana leaves with Agrobacterium strain GV2260 carrying the $A R B 93 B$ GFP construct. Agrobacterium strain GV2260 carrying the GFP construct served as a control. No cell death or phenotypic change was observed in the infiltrated zones expressing $A R B 93 B-G F P$ or $G F P$. The perception of bacterial flagellin by the receptor kinase FLS2 is one of the best-understood PTI responses (Gómez-Gómez et al. 2001). In addition, chitin oligosaccharides from fungal cell walls are perceived by CERK1 (Liu et al. 2012). The conserved peptide of flagellin, flg22, and chitin was used in assays to induce PTI such as ROS production. Therefore, we performed ROS assays to evaluate whether Arb93B can suppress flg22 or chitin-induced ROS production. Leaf disks were taken from $N$. benthamianainfiltrated zones expressing GFP or $A R B 93 B-G F P$ at $2 \mathrm{dpi}$, and treated with $100 \mathrm{nM}$ flg22 or chitin at $200 \mu \mathrm{g} / \mathrm{ml}$. ROS production was measured at 100-s intervals for a period of $50 \mathrm{~min}$. Both flg22-induced and chitin-induced ROS accumulation in leaves expressing $A R B 93 B-G F P$ was significantly reduced in comparison with infiltrated control leaves expressing GFP only (Fig. 6). However, overall chitin-induced ROS accumulation was lower compared with flg22-induced ROS (Fig. 6). No significant ROS burst was detected in controls without flg22 or chitin treatment. Our results indicate that Arb93B reduces flg22- and chitin-induced ROS production, suggesting that Arb93B suppresses one of the earliest events in PTI responses.

Bax-induced PCD is associated with ROS accumulation (Kawai-Yamada et al. 2004). Because Arb93B can suppress ROS production, it might also suppress PCD. To assess whether this is the case, we performed PCD suppression assays using the
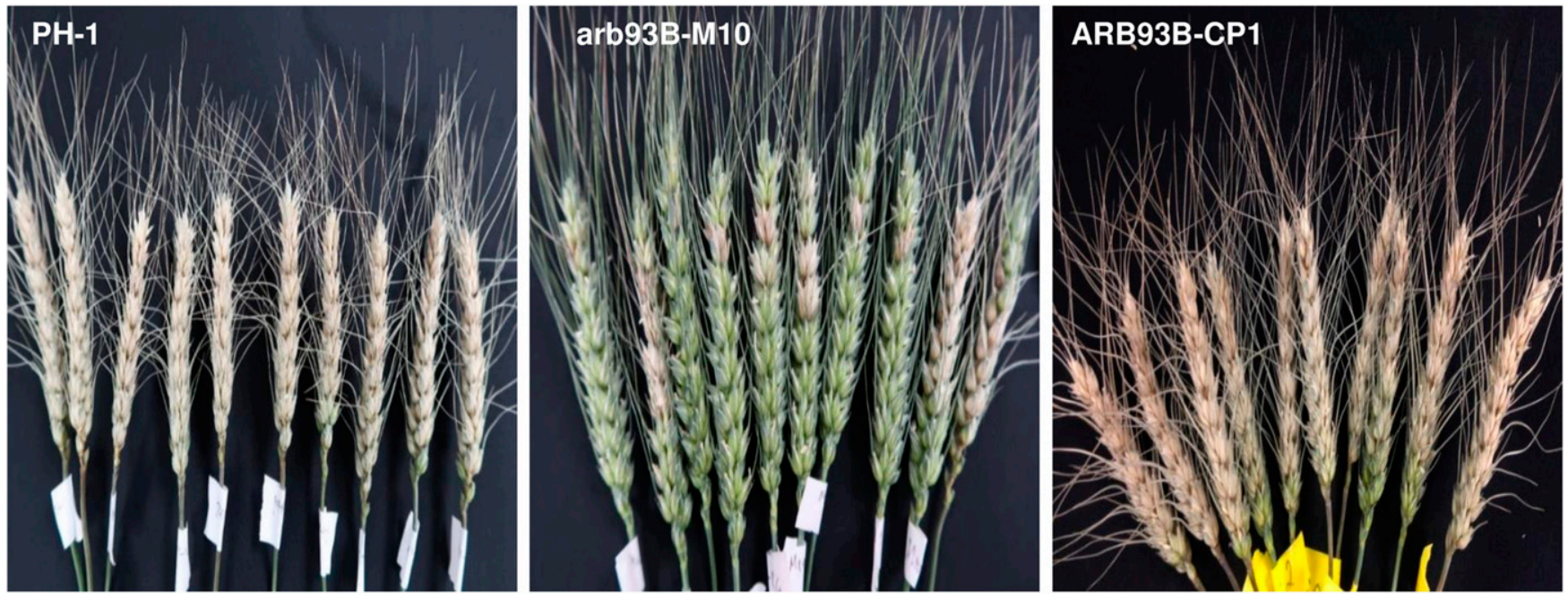

Fig. 3. Disease symptoms in wheat cultivar Norm inoculated with Fusarium graminearum strain and mutant. Point inoculation (10- $\mu$ spore suspension containing 1,000 conidia) was performed on Norm wheat florets with F. graminearum wild-type PH-1 and arb93B mutant M10 and complemented mutant CP1. Photographs were taken 21 days postinoculation.

A

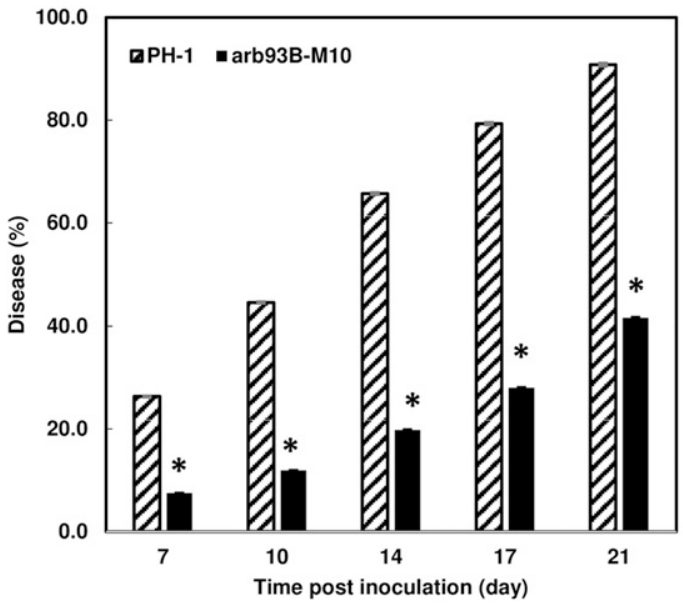

B

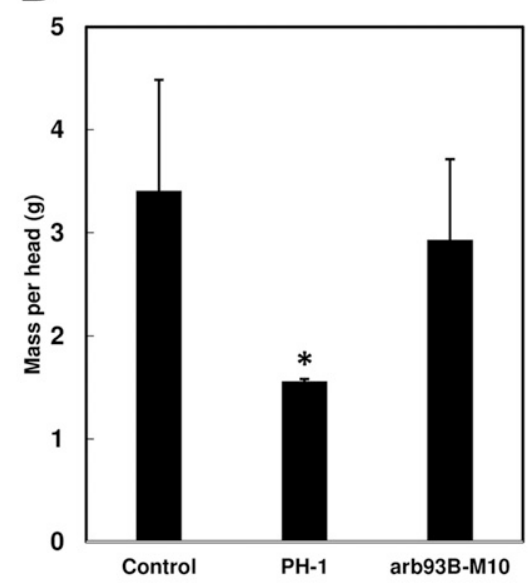

C

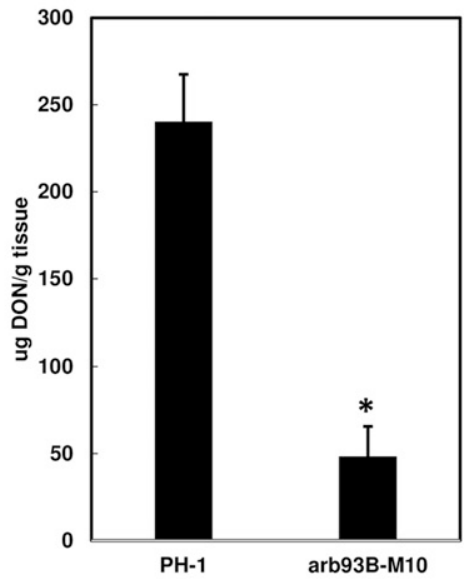

Fig. 4. Pathogenesis assay of $a r b 93 B$ mutants. Point inoculation (10- $\mu$ l spore suspension containing 1,000 conidia) was performed on Norm wheat florets with Fusarium graminearum wild-type PH-1 and $\operatorname{arb} 93 \mathrm{~B}$ mutant M10. A, Fusarium head blight disease progression measured by the percentage of florets infected at 7, 10, 14, 17, and 21 days postinoculation (dpi); B, head weight measure at 21 dpi; and C, deoxynivalenol (DON) was extracted and analyzed by gas chromatography-mass spectrometry at 21 dpi. Bars represent the average and standard error of 24 inoculated head with each strain; and asterisk (*) indicates significant difference at the $P<0.05$ level by one-way analysis of variance. 
cell death inducer Bax. Agrobacterium strains carrying $A R B 93 B-G F P$ or Bax construct were separately infiltrated or coinfiltrated into $N$. benthamiana leaves. The leaf zones infiltrated with Agrobacterium carrying Bax alone developed cell death as expected (Fig. 7A), whereas no cell death was observed in the leaves infiltrated with Agrobacterium carrying $A R B 93 B-G F P$ (Fig. 7A). Cell death was found in zones coinfiltrated with GFP and Bax, indicating that PCD was not suppressed by GFP (Fig. 7A). In contrast, no cell death occurred in zones coinfiltrated with $A R B 93 B-G F P$ and Bax, suggesting that Arb93B can suppress Bax-induced PCD (Fig. 7A). Bax antibody indicated Bax protein in infiltrated leaves with Bax and Bax plus GFP vector, whereas as no clear signal was observed in infiltrated leaves coexpressing Bax plus ARB93B-GFP (Fig. 7B). Immunoblot assays using GFP antibody confirmed ARB93B-GFP fusion protein accumulation in infiltrated leaves with $A R B 93 B-G F P$ and Bax plus $A R B 93 B-G F P$ (Fig. 7C). Collectively, results from our infiltration assays suggest that
Arb93B compromises plant immunity by suppressing ROSassociated PCD.

\section{DISCUSSION}

Most microbes secrete arabinanases to participate in the complete degradation of hemicellulose. These enzymes have potential to contribute to the ability of phytopathogenic microbes to cause plant disease. The genome of $F$. graminearum is predicted to encode at least 18 arabinanases, including two exoarabinanases, and, as far as we are aware, none of these enzymes had been functionally characterized for its role in pathogenicity of the fungus prior to this study. Therefore, in this study, we determined whether two $F$. graminearum exo- $\alpha-\mathrm{L}-$ arabinanases, Arb93A and Arb93B, contribute to cause FHB. We demonstrated that the corresponding genes $(A R B 93 A$ and $A R B 93 B$, respectively) are upregulated during development of FHB. However, although deletion of $A R B 93 B$ markedly
A

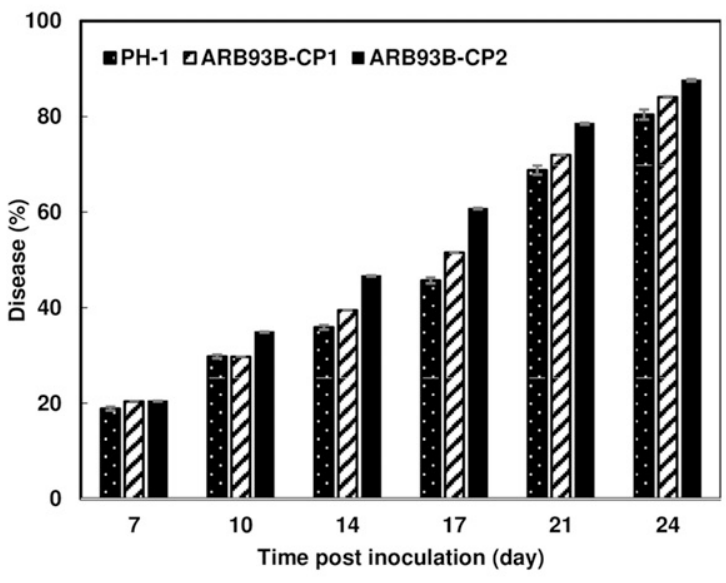

B

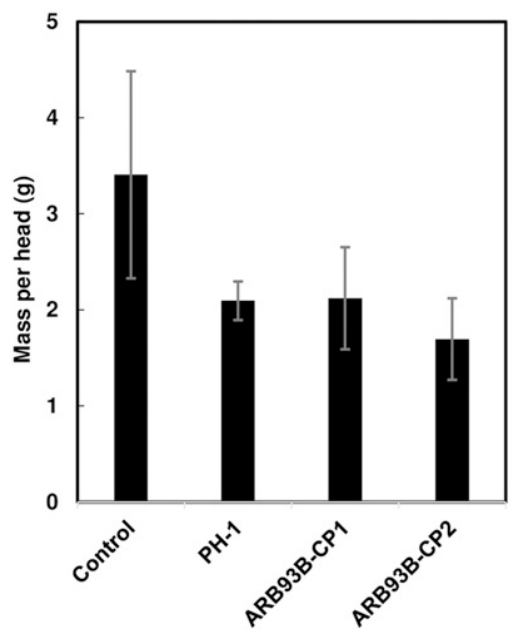

C

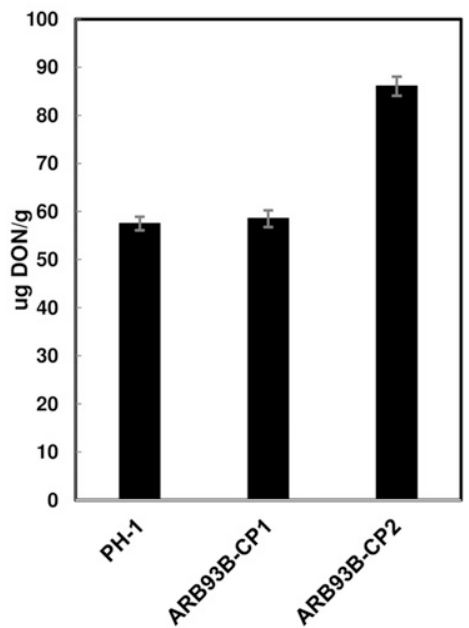

Fig. 5. Complementation assay for $A R B 93 B$ complemented mutants. Point inoculation (10- $\mu 1$ spore suspension containing 1,000 conidia) was performed on Norm wheat florets with Fusarium graminearum wild-type PH-1 and ARB93B complemented mutant CP1 and CP1. A, FHB disease progression measured by the percentage of florets infected at 7, 10,14,17, and 21 days postinoculation (dpi); B, head weight measure at 21 dpi; and $\mathbf{C}$, deoxynivalenol (DON) was extracted and analyzed by gas chromatography-mass spectrometry at 21 dpi. Bars represent the average and standard error of 24 inoculated head with each strain.

A

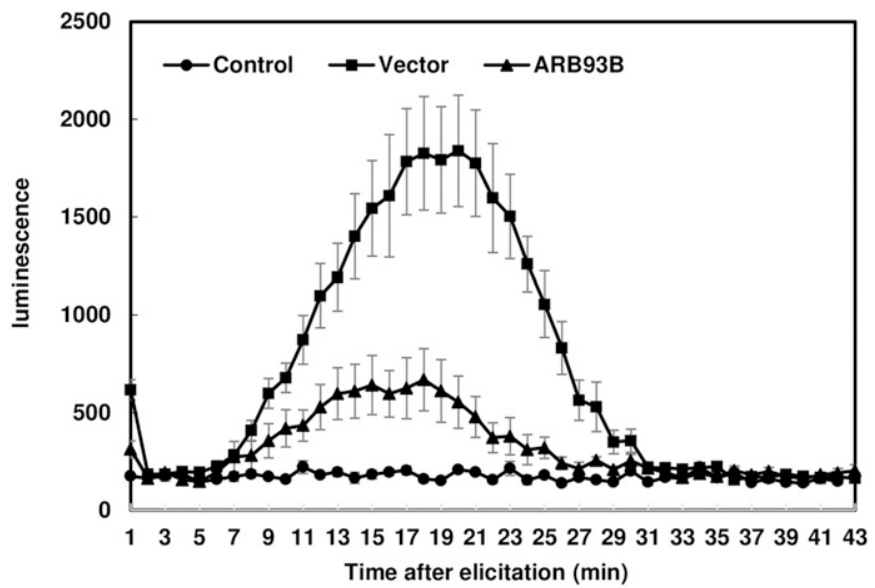

B

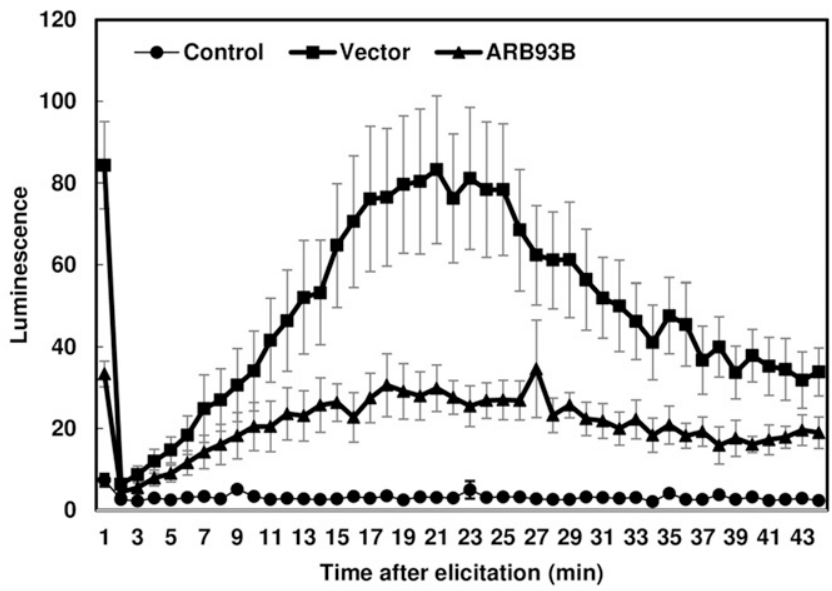

Fig. 6. A and B, ARB93B suppresses flg22- and chitin-induced reactive oxygen species production via transient expression of $A R B 93 B$ in Nicotiana benthamiana leaves. Luminescence was measured in $200 \mu \mathrm{l}$ of assay solution ( $17 \mathrm{mM}$ lumino, $1 \mu \mathrm{M}$ horseradish peroxidase, and $100 \mathrm{nM}$ flg 22 or crab shell chitin at $200 \mu \mathrm{g} / \mathrm{ml}$ ) for $50 \mathrm{~min}$. Leaves expressing green fluorescent protein served as the positive control and assay solution without flg22 or chitin served as the negative control. Bars represent the average of replicates with standard error $(n=8)$. Assays were repeated four times with similar results. 
reduced virulence of $F$. graminearum on wheat heads, deletion of $A R B 93 A$ had no apparent effect on virulence. Furthermore, transient expression of $A R B 93 B$ in $N$. benthamiana reduced flg22-triggered ROS production and suppressed cell death induced by Bax.

FHB pathogenicity assays showed that the $a r b 93 B$ mutant led to significantly reduced FHB symptoms, infection level, and DON production whereas deletion of Arb93A did not affect the virulence of $F$. graminearum. Arb93A can bind linear $\alpha-1,5-$ L-arabinan and release $\alpha-1,5-\mathrm{L}$-arabinobiose from the backbone (Carapito et al. 2009). Substrate assays showed that Arb93A is not capable of cleaving arabinose or arabinooligosaccharide substitutions of a xylan backbone. In addition, no activity was detected on wheat arabinoxylan (Carapito et al. 2009). Because Arb93B shares high homology, similar protein structure, and critical amino acids for enzyme catalytic activity with Arb93A, it was proposed that Arb93B functions as an arabinanase with different substrate specificity (Carapito et al. 2009). However, the arabinanase activity of Arb93B has not been experimentally confirmed. It is possible that the cleavage products of Arb93B are involved in FHB development. Arb93A did not significantly affect FHB development, even though this gene was induced as much as 50-fold at 1 dpi. Although the expression of many CWDEs is induced during plant infection, gene deletion studies indicate that few of them are essential for plant pathogenicity, likely due to the redundancy of CWDEs (Kubicek et al. 2014). For example, several $F$. graminearum xylanases were upregulated during FHB infection but none of them was required for FHB pathogenesis (Sella et al. 2013). The underlying mechanism of Arb93B's effect on FHB is unclear. Based on its predicted function, Arb93B may degrade plant cell wall components to promote $F$. graminearum infection and colonization. The endo-arabinanase BcAral from $B$. cinerea is suggested to function as a virulence factor by helping to overcome the physical barrier to pathogen invasion and spread via hydrolysis of arabinan (Nafisi et al. 2014). Additionally, in a proteomics study, Arb93B (FGSG_03598) but not Arb93A was identified in both in vitro extracellular proteins and in planta, infected with $F$. graminearum (Paper et al. 2007). On the other hand, fungal endoxylanases have been shown to induce necrosis and act as elicitors in plant defense responses independent of their enzymatic activity (Enkerli et al. 1999; Furman-Matarasso et al. 1999). Based on our transient expression results, it is also possible that Arb93B is involved in FHB pathogenesis independent of its enzyme function, or that the cleavage products from Arb93B act as PAMPs or other signal compounds to suppress ROS-associated plant defense responses.

Based on the presence of a chloroplast transit sequence in Arb93B, we predicted that it would be targeted to chloroplasts. However, the Arb93B-GFP generated in this study accumulated in the cytoplasm and nucleus rather than chloroplasts. Using Agrobacterium-mediated transient expression, several effectors, including $P$. syringae HopI1 and HopN1, were found to target the chloroplast to suppress plant defense responses (Jelenska et al. 2007; Rodríguez-Herva et al. 2012). The predicted chloroplast localization of Arb93B was the key reason that prompted us to investigate the role of Arb93B during $F$. graminearum pathogenesis. Surprisingly, neither GFPArb93B fusion protein accumulated in chloroplasts during a transient expression in $N$. benthamiana. It has been reported that the $P$. syringae effector HopK1 containing a chloroplast-targeting

\section{A}

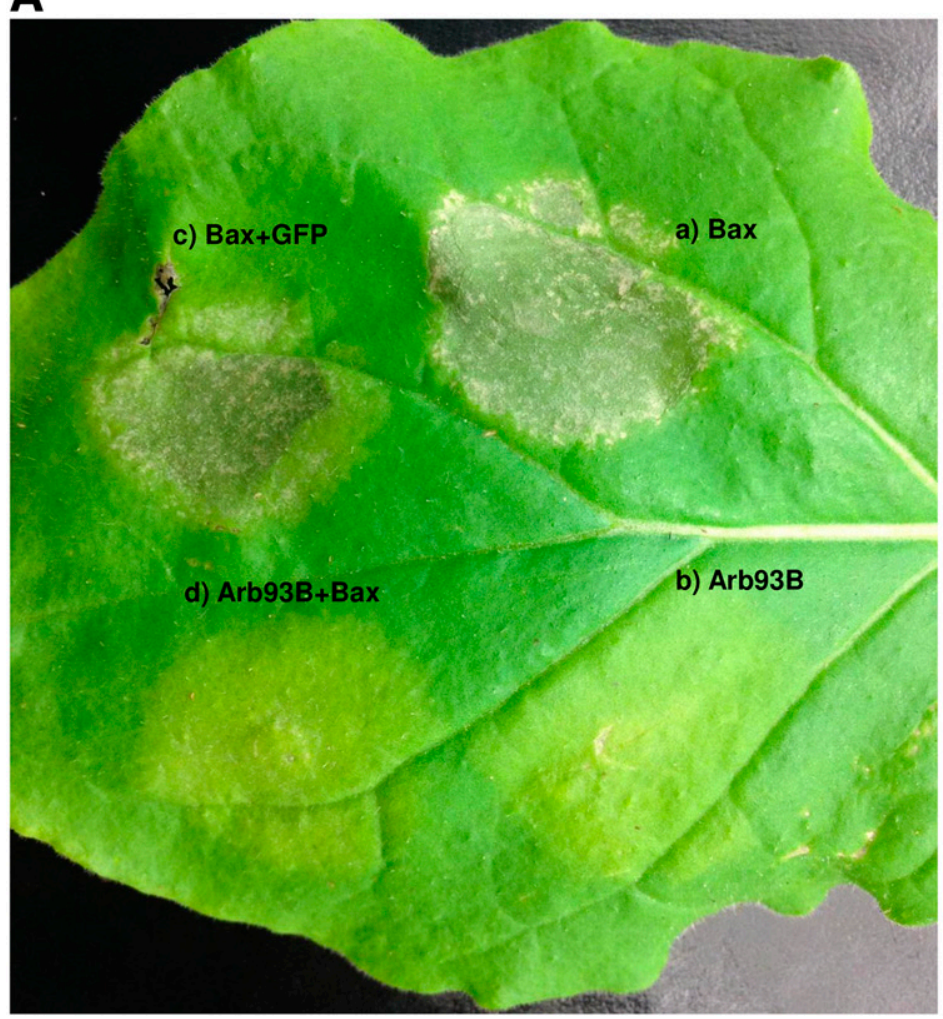

B

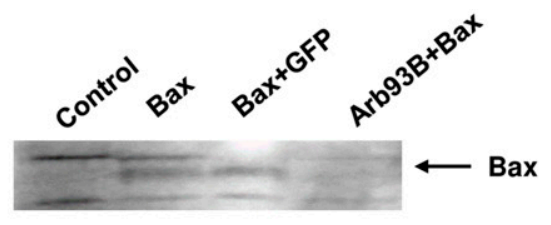

C

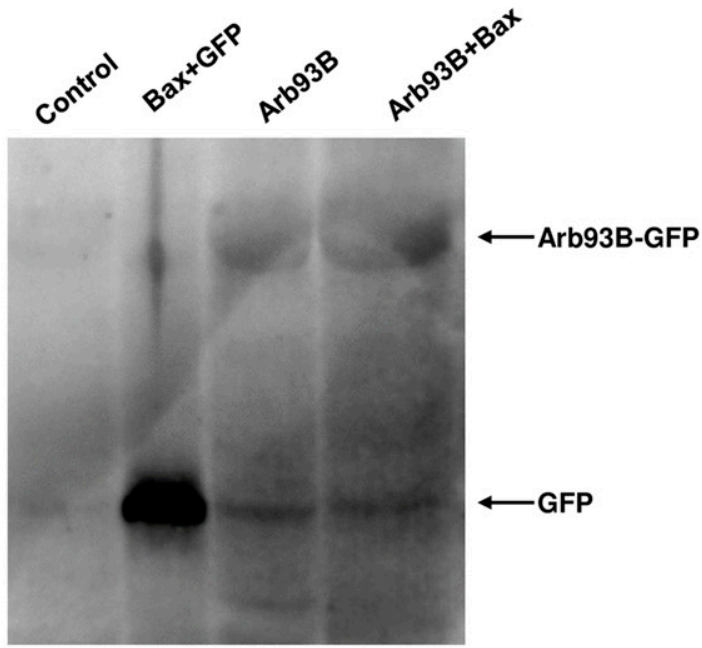

Fig. 7. Bax-induced programmed cell death suppressed by ARB93B via Agrobacterium-mediated transient expression in Nicotiana benthamiana leaves. Leaves of $N$. benthamiana were infiltrated with Agrobacterium strain GV2260 expressing ARB93B, Bax, the mixture of $A R B 93 B$ plus Bax, or green fluorescent protein $(G F P)$ plus Bax. A, N. benthamiana leaf 5 days after agrobacteria infiltration; a, cell death induced by Bax; b, no symptom induced by Arb93B-GFP; c, cell death induced by Bax mixed with GFP vector as a control; and d, suppression of Bax-induced cell death by Arb93B-GFP. Experiments were performed three times with similar results. Immunoblot detection of proteins from $N$. benthamiana leaves transiently expressed the indicated constructs with B, Bax antibody and C, GFP antibody. Noninoculated leaves served as the control. 
peptide was localized in the cytoplasm and nucleus via transient expression in $N$. benthamiana; however, this effector was found to target the chloroplasts in transgenic Arabidopsis (Liu et al. 2012). It remains unclear why different results can be obtained for cell localization in transient versus transgenic expression. Although our results suggest that Arb93B localized to the cytoplasm and nucleus, additional studies using transgenic approaches or immunological detection methods with $F$. graminearum-infected wheat tissue are required to determine unequivocally that Arb93B does or does not localize in chloroplasts.

The ability of Arb93B to suppress flg22- and chitin-trigged ROS burst and Bax-induced cell death in the transient expression system indicates that Arb93B interferes with common targets of the plant immunity pathway. Although the two PAMPs (flagellin from bacteria and chitin from fungal cell wall) are unrelated and perceived by different receptors, a recent study has demonstrated that the majority of effectors suppressed both flg22- and chitin-induced plant immune responses (Gimenez-Ibanez et al. 2018). The rapid ROS production in response to pathogen infection is important to establish plant immune responses. Enhanced ROS accumulation and amplification of ROS signals lead to PCD (Torres et al. 2006). Therefore, many pathogens employ effectors to downregulate ROS-associated defense responses. The Ustilago maydis Pep1 effector involved in initial cell wall penetration suppresses ROS production by inhibiting maize peroxidase POX12 activity (Hemetsberger et al. 2012). The F. oxysporum effector Avr2 inhibits ROS generation, MAPK upregulation, and callose deposition induced by flg22 (Di et al. 2017). Bax localizes to the mitochondria and induces ROS productionassociated cell death (Kawai-Yamada et al. 2004; Lacomme and Santa Cruz 1999). Most of the 169 tested Phytophthora sojae effectors have been reported to suppress PCD induced by Bax (Q. Wang et al. 2011). Multiple small cysteine-rich effectors from wheat rust fungi have been demonstrated to suppress PCD caused by several cytotoxic effector resistance genes, and one effector was associated with inhibition of both PCD and ROS burst triggered by flg22 (Ramachandran et al. 2017). The suppression of plant immunity by these effectors indicates that they may share ROS-mediated signals that lead to PCD. The Pseudomonas syringae HopN1 effector targets plant chloroplast, blocks ROS production, and suppresses the function of photosystem II and plant immune responses (RodríguezHerva et al. 2012). In addition, two PCD suppressors (AvrRpm1 and AvrRpt 2 effectors from $P$. syringae) were found to target RIN4 and manipulate plant resistance (Axtell and Staskawicz 2003; Mackey et al. 2003). Cell wall arabinan contributes to plant cell wall flexibility and is essential for guard cell function. Stomatal closure is part of plant defense response against bacterial invasion (Melotto et al. 2006). We suspect that degradation of arabinan may affect stomatal opening and closing and, thereby, interfere with ROS-associated plant defense responses. Further investigations are needed to characterize the underlying mechanism of Arb93B suppressing ROS and PCD.

We demonstrated that Arb93B increased FHB susceptibility in the spring wheat cultivar Norm by mutagenesis and that Arb93B suppressed ROS-associated plant immune responses via transient expression in $N$. benthamiana. In addition to degradation of the plant cell wall for penetration and colonization, fungal pathogens secrete multiple virulence proteins to interfere with the plant defense system during infection (Lo Presti et al. 2015). For example, the chorismate mutase Cmul secreted by $U$. maydis reduces salicylate acid biosynthesis by degrading salicylic acid (SA) precursors such as chorismate, and interferes with SA-mediated immune responses (Djamei et al. 2011). The Ecp6 effector of Cladosporium fulvum sequesters chitin fragments that are released from the fungal cell wall to prevent the recognition of chitin fragments and avoid PTI response (de Jonge et al. 2010). A secreted lipase from $F$. graminearum inhibited callose biosynthesis and plant immunity by releasing free fatty acids (Blümke et al. 2014). Trichothecene T-2 produced by $F$. sporotrichioides-induced plant defense genes, generated ROS, and stimulated necrotic lesions in Arabidopsis (Nishiuchi et al. 2006). Infiltration of wheat leaves with DON resulted in ROS production, defense gene induction, and cell death (Desmond et al. 2008). During wheat infection, necrosis is a typical symptom of FHB. Transcriptome studies showed that the expression of extracellular ROS-producing enzymes was induced during $F$. graminearum infection of wheat coleoptiles (Zhang et al. 2012). Arb93B may suppress ROS generation and defense response induced by the mycotoxin DON or other enzymes to promote disease during the early stages of infection. Although plant defense systems are conserved across monocots and dicots, it will be of interest to determine whether Arb93B can suppress ROS production in $F$. graminearum host plants such as wheat.

Collectively, the results of this study indicate that Arb93B enhances FHB susceptibility in spring wheat by suppressing ROS-associated plant defense responses. Further investigations are needed to determine the underlying mechanism by which Arb93B interacts with plant defense pathways. Two key questions are: Is the effect of Arb93B directly related to its arabinanase activity (e.g., through release of arabinose that affects plant defense) or is the effect of Arb93B mediated by its presence in chloroplasts? Such studies may aid in the development of novel methods to control FHB and mycotoxin contamination.

\section{MATERIALS AND METHODS}

\section{Strains and plants growth.}

The wild-type strain $F$. graminearum $\mathrm{PH}-1$ was maintained on V8 juice agar with a cycle of $12 \mathrm{~h}$ of light and $12 \mathrm{~h}$ of darkness at $28^{\circ} \mathrm{C}$ under ultraviolet light. For mutants, V8 juice agar was amended with hygromycin or geneticin at a concentration of $150 \mathrm{mg} / \mathrm{liter}$. Escherichia coli and Agrobacterium were grown in Luria-Bertani (LB) medium with addition of different antibiotics: kanamycin at $100 \mathrm{mg} / \mathrm{liter}$ and spectinomycin at $100 \mathrm{mg} / \mathrm{liter}$.

Spring wheat Norm was used in FHB virulence assays. Five wheat seeds were planted in a nine-inch bucket containing SunShine Mix (Sun Gro Horticulture, Agawam, MA, U.S.A.) supplemented with Osmocote and micromax and grown in controlled chambers under a cycle of $14 \mathrm{~h}$ of light and $10 \mathrm{~h}$ of darkness at 23 and $20^{\circ} \mathrm{C}$, respectively, with $50 \%$ relative humidity.

Seed of $N$. benthamiana were germinated in chambers with cycles of $16 \mathrm{~h}$ of light and $8 \mathrm{~h}$ of darkness at $25^{\circ} \mathrm{C}$. The seedlings were then transferred into soil in plastic containers and grown in the growth chamber under the same condition.

\section{Mutant generation and fungal transformation.}

$A R B 93 B$ deletion mutants were generated by the split marker method (Brown et al. 2014). Primers for amplification of upstream and downstream fragments of $A R B 93 B$ and $h y g B$ fragments are listed in Supplementary Table S1. Briefly, a 1,827-bp DNA fragment upstream of the start codon and a 1,805-bp fragment downstream of the stop codon of $A R B 93 B$ were amplified from PH-1 genomic DNA by PCR. The third fragment (HY) containing the $5^{\prime}$ two-thirds of the $h y g B$ gene and the fourth fragment (YG) corresponding to the $3^{\prime}$ two-thirds of hyg $B$ were amplified as described (Brown et al. 2014). Two 
split-marker fragments were generated by combination of upstream, downstream, and $h y g B$ fragments.

Protoplasts were generated by digestion of germinating macroconidia with driselase, chitinase, and lysing enzyme (SigmaAldrich, St. Louis, MO, U.S.A.), as described (Brown et al. 2014). The two purified nested PCR fragments were introduced into $\mathrm{PH}-1$ protoplast via polyethylene glycol-mediated transformation. The three homologous recombination events resulted in replacement of the 1,170-bp $A R B 93 B$ coding region with the 2,500-bp hygB resistance cassette. Transformants were selected with $h y g B$ at $150 \mathrm{mg} /$ liter. Target gene deletions were confirmed by PCR. Whole genome sequencing was used to confirm the absence of ectopic $h y g B$ insertion. DNA was prepared for genome sequencing based on methods described by Kelly and Ward (2018). Sequencing reads were trimmed to remove adaptors, low-quality $(\mathrm{Q}<20)$ bases, and ambiguous nucleotides, and filters were applied to eliminate DNA contaminants. Reads were de novo assembled using default parameters in CLC Genomics Workbench, version 9.5.2. BLAST was used to confirm the absence of off-target hyg $B$ insertions among the assembled contigs. Single spores of hygromycin-resistant mutants were maintained on V8 juice agar containing hygB at $150 \mu \mathrm{g} / \mathrm{ml}$.

Although we confirmed that $A R B 93 B$ was replaced by the $h y g B$ fragment in the $a r b 93 B$ mutants, we found that multiple hyg $B$ fragments were present in the insertion site by wholegenome sequencing. Therefore, one-step construction of Agrobacterium-recombination-ready plasmids (OSCAR) and Agrobacterium-mediated transformation was used to create ARB93A mutant following published protocols (Mullins et al. 2001; Paz et al. 2011). A 1,827-bp DNA fragment upstream of the start codon and a 1,805-bp fragment downstream of the stop codon of $A R B 93 A$ were amplified from $\mathrm{PH}-1$ genomic DNA with primer pairs, including the BP cloning site. The BP clonase reaction was performed with OSCAR plasmids and transformed into $E$. coli-competent cells. The correct construct was confirmed with PCR using two primer pairs (OSC-F/HygR210 and Hyg-F850/OSC-R) and was used to transform Agrobacterium strain AGL1 by heat shock. Agrobacterium strain AGL1 carrying an ARB93A deletion construct was grown overnight in LB medium supplemented with spectinomycin. Spores of $F$. graminearum strain $\mathrm{PH}-1$ were collected from 6- to 7 -day-old cultures grown at $25^{\circ} \mathrm{C}$ under ultraviolet fluorescence. The collected spores (approximately $1 \times 10^{6} \mathrm{ml}$ ) were mixed with Agrobacterium strain AGL1 (optical density at $600 \mathrm{~nm}\left[\mathrm{OD}_{600}\right]$ of approximately 0.4$)$. The mix solution ( $200 \mu \mathrm{l}$ per plate) was plated on a $0.45-\mu \mathrm{m}$ pore nitrocellulose filter (Whatman, Hillsboro, OR, U.S.A.) and spread on coculture medium with the addition of $200 \mu \mathrm{M}$ acetosyringone. Following incubation at $25^{\circ} \mathrm{C}$ for 2 days, the filters were transferred to V8 juice plates containing hygB at $150 \mu \mathrm{g} / \mathrm{ml}$ and $200 \mu \mathrm{M}$ cefotaxime (Sigma-Aldrich). Individual mutants were transferred to new V8 juice plates containing hygromycin and cefotaxime for DNA isolation and whole-genome sequencing. Replacement of $A R B 93 A$ with the $h y g B$ fragment in the construct was confirmed by PCR using two primer pairs, OSCF/Hyg-R210 and Hyg-F850/OSC-R, which produced bands of 1,322 and $1,466 \mathrm{bp}$, respectively. Whole-genome sequencing was used to confirm the absence of ectopic $h y g B$ insertion, as described above.

\section{Complementation of arb93B mutants.}

For $a r b 93 B$ mutant complementation experiments, Agrobacterium-mediated transformation was performed as described (Bahadoor et al. 2016). A PCR fragment containing the $A R B 93 B$ coding sequence region plus $612 \mathrm{bp}$ upstream of the start site and $600 \mathrm{bp}$ downstream of the stop codon was amplified with primers Arb93B-5'-up and Arb93B-3'-down containing overhangs. The pRF-GU vector was digested with PacI and Nt.BbcCI (New England Biolabs, Ipswich, MA, U.S.A.). The amplified PCR products were ligated with the linearized pRF-GU using the USER enzyme (New England Biolabs). The ligation was performed at $37^{\circ} \mathrm{C}$ for $20 \mathrm{~min}$, followed by $25^{\circ} \mathrm{C}$ for $20 \mathrm{~min}$. One-fifth of the ligation mix was transformed into E. coli-competent cells TOPO10 (Invitrogen, Carlsbad, CA, U.S.A.). PCR was used to screen positive colonies. Plasmids containing the $A R B 93 B$ coding region were sequenced, confirmed as consensus sequence, and then introduced into Agrobacterium strain AGL1 by heat shock. Mutant $a r b 93 B$ spores were collected and transformed with Agrobacterium strain AGL1 carrying the $A R B 93 B$ gene, as described above. The selection of complemented mutants was performed on V8 juice agar with the addition of geneticin at $150 \mathrm{mg} / \mathrm{liter}$. Confirmation of complemented mutants containing $A R B 93 B$ was performed by PCR using primers Arb93BORF-5' and Arb93B-ORF-3'. Single spores of complemented mutants were isolated, confirmed, and used for FHB virulence analysis.

\section{FHB virulence assays.}

The virulence of $a r b 93 A$ and $a r b 93 B$ mutants was assessed on susceptible wheat cultivar Norm by single floret inoculation (Dyer et al. 2005). F. graminearum $\mathrm{PH}-1$, arb93A-M1 and -M2, arb93B-M10 and -M11. and complemented mutant $A R B 93 B$ -CP1 and -CP2 inocula were obtained from 4-day-old mung bean liquid cultures. The macroconidia were passed through a $40-\mu \mathrm{M}$ cell strainer (Biologix, Jinan, Shandong, China) and centrifuged for $10 \mathrm{~min}$ at 3,000 rpm. The pellet was suspended in water and adjusted to a concentration of $10^{5}$ conidia $/ \mathrm{ml}$. At anthesis, wheat heads were injected with $10 \mu \mathrm{l}$ of conidia solution from $\mathrm{PH}-1$, or one of the mutants or complemented mutants into one floret in the third spikelet from the top of the wheat head. Inoculated wheat heads were covered with a plastic bag for 3 days to maintain high humidity. FHB disease was scored at 7, 10, 14, 17, and $21 \mathrm{dpi}$. At $21 \mathrm{dpi}$, individual wheat heads were harvested and weighed. Two wheat heads were combined, lyophilized, and pulverized in a 70-ml silver aluminum seamless screw-top can (Freund Container \& Supply, Lisle, IL, U.S.A.) with five to six metal $10-\mathrm{mm}$ diameter stainless-steel grinding balls (SPEX SamplePrep, Metuchen, NJ, U.S.A.). The pulverized tissues were analyzed for DON content using GC-MS. Statistical analysis was performed with one-way analysis of variance. Six virulence assays were performed for $\operatorname{arb} 93 B$ mutants, with 16 or 24 wheat heads inoculated in each assay. Two assays were performed for $a r b 93 \mathrm{~A}$ mutants and $A R B 93 B$ complemented mutants, with 16 or 24 wheat heads inoculated in each assay.

\section{Gene expression in inoculated wheat heads by quantitative PCR.}

For gene expression studies, wheat heads were inoculated by dipping in a PH-1 suspension of $10^{5}$ conidia/ml containing $0.02 \%$ Tween 20 . The experiments were performed with three replicates. Wheat heads were collected at 1, 2, 3, 4, 5, 6, and 7 dpi. At each time point, two heads were collected and combined as one sample. Three replicates were performed. Wheat heads were lyophilized and pulverized as described above. RNA was extracted from pulverized wheat head tissue using Trizol combined with column purification and on column digestion according to the manufacturer's instructions (Thermo Fisher Scientific, Waltham, MA, U.S.A.). First-strand cDNA was synthesized and reverse-transcription quantitative PCR was performed in a CFX96 real-time PCR detection system (BioRad, Hercules, CA, U.S.A.). Gene expression levels were calculated with the $2^{-\Delta \Delta \mathrm{Ct}}$ values using reference cDNA from 
7-day-old culture on V8. $\beta$-Tubulin was amplified and used as an internal control for normalization of gene expression values.

\section{Toxin production in liquid culture and in planta.}

$F$. graminearum $\mathrm{PH}-1$ produces $15-\mathrm{ADON}$ in liquid culture (Lee et al. 2014). 15-ADON was measured in PH-1, arb93B mutants M10 and M11, and $a r b 93 A$ mutant M1 grown in liquid agmatine media (Gardiner et al. 2009). Cultures were grown in $20 \mathrm{ml}$ of agmatine media for 7 days on a rotary shaker at $200 \mathrm{rpm}$ in the dark at $28^{\circ} \mathrm{C}$, then extracted with $8 \mathrm{ml}$ of ethyl acetate. Each extract was dried under a nitrogen stream, then suspended in $1 \mathrm{ml}$ of ethyl acetate and analyzed by GC-MS. GC-MS analysis was performed on a Hewlett Packard 6890 gas chromatograph fitted with an HP-5MS column $(30 \mathrm{~m}, 0.25 \mathrm{~mm}$, $0.25 \mu \mathrm{m})$ and a 5973 mass detector. Helium was used as the carrier gas with a $20: 1$ split ratio and a $20 \mathrm{ml} / \mathrm{min}$ split flow. The column was held at $150^{\circ} \mathrm{C}$ for $1 \mathrm{~min}$ following injection, then heated to $280^{\circ} \mathrm{C}$ at $30^{\circ} \mathrm{C} / \mathrm{min}$, where it was held for $3.5 \mathrm{~min}$. Under these conditions, $15-\mathrm{ADON}$ is detected at $7.1 \mathrm{~min}$.

Wheat heads inoculated with PH-1, arb93B mutant M10, and complemented mutants CP1 and CP2 were harvested at $21 \mathrm{dpi}$, freeze dried, and pulverized as described above. Ground tissue was extracted with acetonitrile/water (86:14), and extracts were purified with Romer MycoSep 225 Trich cartridges and dried under a stream of nitrogen. Trimethylsilyl (TMS) derivatives were prepared by adding $100 \mu \mathrm{l}$ of a 100:1 freshly prepared mixture of N-trimethylsilylimadazole/trimethylchlorosilane to the dried extracts. TMS derivatives of purified DON were prepared in the same way. DON concentrations in ground tissues were determined with GC-MS using the same temperature conditions as abov, but with a splitless inlet and selective ion monitoring for the DON triTMS derivative.

\section{Localization of Arb93B.}

To investigate Arb93B localization, two PCR products, one fragment encoding Arb93B mature protein and the other fragment encoding a chloroplast targeting signal peptide, were amplified from PH-1 genomic DNA. The PCR products for the Arb93B mature protein sequence containing attb1 and attb2 linkers were introduced into the $\mathrm{pDONR}^{\mathrm{TM}} 221$ plasmid using the Gateway BP reaction (Invitrogen) and transformed into E. coli TOPO10-competent cells. The pDONR ${ }^{\mathrm{TM}} 221$ plasmids containing $A r b 93 B$ consensus sequence were used for Gateway LR reactions with vector pGWB405 (Nakagawa et al. 2007). The amplified PCR products for the chloroplasttargeting peptide of Arb93B were cloned into a binary vector (pGDY), in which gene expression was under control of a CaMV 35S promoter (Goodin et al. 2002). The recombinant plasmids were screened, verified by sequencing, and then transformed into Agrobacterium tumefaciens strain GV2260 by heat shock.

For transient expression in $N$. benthamiana, the experiment was performed as described (Hao et al. 2014). Briefly, the A. tumefaciens GV2260 strain containing different constructs was cultured, washed, and suspended in Agromix $(10 \mathrm{mM}$ $\mathrm{MgCl}_{2}, 10 \mathrm{mM}$ morpholineethanesulfonic acid, and $100 \mu \mathrm{M}$ acetosyringone). The cell suspension was adjusted to an $\mathrm{OD}_{600}$ of 0.6 and infiltrated into 4- to 5-week-old $N$. benthamiana leaves with a 1-ml needleless syringe. Three days after infiltration, the infiltrated zone was excised and the epidermal layers were peeled for photographs with fluorescence microscope Axio Imager A1 under ultraviolet light.

\section{ROS assay.}

To examine whether $A R B 93 B$ affects PTI, ROS detection was performed using a luminol-based chemiluminescence assay
(Hao et al. 2014). A. tumefaciens GV2260 strains carrying GFP or $A R B 93 B-G F P$ with an $\mathrm{OD}_{600}$ of 0.5 were infiltrated to $N$. benthamiana leaves as described above. At 2 dpi, eight leaf discs were removed from infiltrated zones with a cork borer and floated on water overnight. Prior to ROS measurement, water was replaced with $200 \mu \mathrm{l}$ of the assay solution consisting of $17 \mathrm{mM}$ lumino L012 (Sigma-Aldrich), $1 \mu \mathrm{M}$ horseradish peroxidase (Sigma-Aldrich), and $100 \mathrm{nM}$ flg22 (AnaSpec Inc., Tremont, CA, U.S.A.) or crab shell chitin (Sigma-Aldrich) at $200 \mu \mathrm{g} / \mathrm{ml}$. Luminescence was measured for $50 \mathrm{~min}$ using the Synergy HT and Gen5 software (BioTek Instruments, Inc., Winooski, VT, U.S.A.).

\section{Cell death suppression assay in $N$. benthamiana.}

For cell death suppression assays, Agrobacterium carrying $A R B 93 B-G F P$ and Agrobacterium carrying Bax were coinfiltrated into 4- to 5-week-old $N$. benthamiana leaves (Ramachandran et al. 2017). Agrobacterium containing different constructs were prepared as described above and adjusted to an $\mathrm{OD}_{600}$ of approximately 0.6. Each of the two culturesAgrobacterium carrying Bax and Agrobacterium carry $A R B 93 B-G F P$ or $G F P$ alone - was mixed in a $1: 1$ ratio before infiltration. Agrobacterium strains carrying Bax or Arb93BGFP construct were infiltrated in parallel as controls. Symptom development was observed visually from 3 to 7 days after infiltration and leaves were photographed at 5 days after infiltration. Each experiment was performed on three leaves of each plant and three plants were used. The experiments were repeated at least three times with similar results.

Western blotting. For each sample, $N$. benthamiana leaves were taken at $3 \mathrm{dpi}$ and the tissue was ground to a powder with liquid nitrogen. The powder was transferred to a $15-\mathrm{ml}$ conical tube and weighed, and two volumes of RIPA extract buffer were added $(50 \mathrm{mM}$ Tris- $\mathrm{HCl}$ [pH 7.5], $150 \mathrm{mM} \mathrm{NaCl}, 1 \%$ sodium deoxycholate, $1 \%$ Triton $\mathrm{X}-100,0.1 \%$ sodium dodecyl sulfate [SDS], $1 \mathrm{mM}$ phenylmethane sulfonyl fluoride, and $1 \times$ Sigma Protease Inhibitor Cocktail). The sample was incubated for $30 \mathrm{~min}$ and then centrifuged. The supernatant was transferred to a new tube and the protein concentration was measured by Bradford assays. Extracts were diluted to protein at $5 \mathrm{mg} / \mathrm{ml}$ and stored at $-80^{\circ} \mathrm{C}$.

Proteins $(50 \mu \mathrm{g} / \mathrm{sample})$ were separated by SDS polyacrylamide gel electrophoresis using a $12 \%$ acrylamide gel (GFP) or a 10-to-20\% acrylamide gradient gel (Bax). Proteins were transferred to nitrocellulose membranes using an iBlot 2 dry blotting system (Thermo-Fisher, Carlsbad, CA, U.S.A.). Membranes were incubated with phosphate-buffered saline (PBS) containing 5\% bovine serum albumin (PBS+BSA) for 30 min and then with the primary antibody solution (PBS+BSA containing antibody at $10 \mathrm{ng} / \mathrm{ml}$ for GFP or $110 \mathrm{ng} / \mathrm{ml}$ for Bax) for $1 \mathrm{~h}$. Unbound antibody was removed by washing three times with PBS containing $0.05 \%$ Tween 20 (PBST). Membranes were then incubated with secondary antibodies (goat antirabbit immunoglobulin $\mathrm{G}$ conjugated to horseradish peroxidase and antibody at $300 \mathrm{ng} / \mathrm{ml}$ in PBS+BSA) for $30 \mathrm{~min}$, washed three times in PBST, and incubated with substrate (SuperSignal West Pico PLUS; Thermo-Fisher) for $5 \mathrm{~min}$. Images were taken with a c400 imager (Azure Biosystems, Dublin, CA, U.S.A.). Primary and secondary antibodies were purchased from Abcam (San Francisco, CA, U.S.A.).

\section{ACKNOWLEDGMENTS}

We thank T. Usgaard, N. Orwig, S. Folmar, and C. Hodges for their excellent technical help; D. Brown for pHygAsc plasmid; S. Gold for OSCAR plasmids; L. Harris (Agriculture and Agri-Food Canada) for pRFGU vector; and S. Ramachandran (Washington State University) for Bax construct. 


\section{LITERATURE CITED}

Abramovitch, R. B., Kim, Y. J., Chen, S., Dickman, M. B., and Martin, G. B. 2003. Pseudomonas type III effector AvrPtoB induces plant disease susceptibility by inhibition of host programmed cell death. EMBO J. 22:60-69.

Axtell, M. J., and Staskawicz, B. J. 2003. Initiation of RPS2-specified disease resistance in Arabidopsis is coupled to the AvrRpt2-directed elimination of RIN4. Cell 112:369-377.

Bahadoor, A., Schneiderman, D., Gemmill, L., Bosnich, W., Blackwell, B., Melanson, J. E., McRae, G., and Harris, L. J. 2016. Hydroxylation of longiborneol by a Clm2-encoded CYP450 monooxygenase to produce culmorin in Fusarium graminearum. J. Nat. Prod. 79:81-88.

Bai, G. H., Desjardins, A. E., and Plattner, R. D. 2002. Deoxynivalenolnonproducing fusarium graminearum causes initial infection, but does not cause disease spread in wheat spikes. Mycopathologia 153 : 91-98.

Beldman, G., Schols, H. A., Pitson, S. M., Searle-van Leeuwen, M. J. F., and Voragen, A. G. J. 1997. Arabinans and arabinan degrading enzymes. Pages 1-64 in: Advances in Macromolecular Carbohydrate Research, Vol. 1. R. J. Sturgeon, ed. JAI Press, Inc., Greenwich, CT, U.S.A

Blümke, A., Falter, C., Herrfurth, C., Sode, B., Bode, R., Schäfer, W., Feussner, I., and Voigt, C. A. 2014. Secreted fungal effector lipase releases free fatty acids to inhibit innate immunity-related callose formation during wheat head infection. Plant Physiol. 165:346-358

Brown, D. W., Busman, M., and Proctor, R. H. 2014. Fusarium verticillioides SGE1 is required for full virulence and regulates expression of protein effector and secondary metabolite biosynthetic genes. Mol. Plant-Microbe Interact. 27:809-823.

Brown, N. A., Antoniw, J., and Hammond-Kosack, K. E. 2012. The predicted secretome of the plant pathogenic fungus Fusarium graminearum: A refined comparative analysis. PLoS One 7:e33731.

Burnaugh, A. M., Frantz, L. J., and King, S. J. 2007. Growth of Streptococcus pneumoniae on human glycoconjugates is dependent upon the sequential activity of bacterial exoglycosidases. J. Bacteriol. 190:221-230.

Carapito, R., Imberty, A., Jeltsch, J. M, Byrns, S. C, Tam, P. H, Lowary, T. L, Varrot A., and Phalip, V. 2009. Molecular basis of arabinobiohydrolase activity in phytopathogenic fungi: Crystal structure and catalytic mechanism of Fusarium graminearum GH93 exo- $\alpha-\mathrm{L}-$ arabinanase. J. Biol. Chem. 284:12285-12296.

Coll, N. S., Epple, P., and Dangl, J. L. 2011. Programmed cell death in the plant immune system. Cell Death Differ. 18:1247-1256.

de Jonge, R., van Esse, H. P., Kombrink, A., Shinya, T., Desaki, Y., Bours, R., van der Krol, S., Shibuya, N., Joosten, M. H., and Thomma, B. P. 2010. Conserved fungal LysM effector Ecp6 prevents chitin-triggered immunity in plants. Science 329:953-955.

Desjardins, A. E., and Hohn, T. M. 1997. Mycotoxins in plant pathogenesis Mol. Plant-Microbe Interact. 10:147-152.

Desmond, O. J., Manners, J. M., Stephens, A. E., Maclean, D. J., Schenk, P. M., Gardiner, D. M., Munn, A. L., and Kazan, K. 2008. The Fusarium mycotoxin deoxynivalenol elicits hydrogen peroxide production, programmed cell death and defence responses in wheat. Mol. Plant Pathol. 9:435-445.

Di, X., Cao, L., Hughes, R. K., Tintor, N., Banfield, M. J., and Takken, F. L. W. 2017. Structure-function analysis of the Fusarium oxysporum Avr2 effector allows uncoupling of its immune-suppressing activity from recognition. New Phytol. 216:897-914.

Djamei, A., Schipper, K., Rabe, F., Ghosh, A., Vincon, V., Kahnt, J., Osorio, S., Tohge, T., Fernie, A. R., Feussner, I., Feussner, K., Meinicke, P., Stierhof, Y. D., Schwarz, H., Macek, B., Mann, M., and Kahmann, R. 2011. Metabolic priming by a secreted fungal effector. Nature 478 : 395-398.

Dou, D., Kale, S. D., Wang, X., Chen, Y., Wang, Q., Wang, X., Jiang, R. H. Y., Arredondo, F. D., Anderson, R. G., Thakur, P. B., McDowell, J. M., Wang, Y., and Tyler, B. M. 2008. Conserved C-terminal motifs required for avirulence and suppression of cell death by Phytophthora sojae effector Avr1b. Plant Cell 20:1118-1133.

Dyer, R. B., Plattner, R. D., Kendra, D. F., and Brown, D. W. 2005. Fusarium graminearum TRI14 is required for high virulence and DON production on wheat but not for DON synthesis in vitro. J. Agric. Food Chem. 53:9281-9287.

Enkerli, J., Felix, G., and Boller, T. 1999. The enzymatic activity of fungal xylanase is not necessary for its elicitor activity. Plant Physiol. 121: 391-398.

Furman-Matarasso, N., Cohen, E., Du, Q., Chejanovsky, N., Hanania, U., and Avni, A. 1999. A point mutation in the ethylene-inducing xylanase elicitor inhibits the $\beta-1-4$-endoxylanase activity but not the elicitation activity. Plant Physiol. 121:345-352.
Galen, J. E., Ketley, J. M., Fasano, A., Richardson, S. H., Wasserman, S. S., and Kaper, J. B. 1992. Role of Vibrio cholerae neuraminidase in the function of cholera toxin. Infect. Immun. 60:406-415.

Gardiner, D. M., Kazan, K., and Manners, J. M. 2009. Nutrient profiling reveals potent inducers of trichothecene biosynthesis in Fusarium graminearum. Fungal Genet. Biol. 46:604-613.

Gimenez-Ibanez, S., Hann, D. R., Chang, J. H., Segonzac, C., Boller, T., and Rathjen, J. P. 2018. Differential suppression of Nicotiana benthamiana innate immune responses by transiently expressed Pseudomonas syringae type III effectors. Front. Plant Sci. 9:688.

Göhre, V., and Robatzek, S. 2008. Breaking the barriers: Microbial effector molecules subvert plant immunity. Annu. Rev. Phytopathol 46:189-215.

Gómez-Gómez, L., Bauer, Z., and Boller, T. 2001. Both the extracellular leucine-rich repeat domain and the kinase activity of FLS2 are required for flagellin binding and signaling in Arabidopsis. Plant Cell 13: $1155-1163$.

Goodin, M. M., Dietzgen, R. G., Schichnes, D., Ruzin, S., and Jackson, A. O. 2002. $p$ GD vectors: Versatile tools for the expression of green and red fluorescent protein fusions in agroinfiltrated plant leaves. Plant J. 31: 375-383.

Guo, M., Tian, F., Wamboldt, Y., and Alfano, J. R. 2009. The majority of the type III effector inventory of Pseudomonas syringae pv. tomato DC3000 can suppress plant immunity. Mol. Plant-Microbe Interact. 22: $1069-1080$

Hao, G., Pitino, M., Ding, F., Lin, H., Stover, E., and Duan, Y. 2014 Induction of innate immune responses by flagellin from the intracellular bacterium, 'Candidatus Liberibacter solanacearum'. BMC Plant Biol. $14: 211$

Hayn, M., Steiner, W., Klinger, R., Steinmüller, H., Sinner, M., and Esterbauer, H. 1993. Bioconversion of Forest and Agricultural Plant Residues. CAB International, Wallingford, UK.

Hemetsberger, C., Herrberger, C., Zechmann, B., Hillmer, M., and Doehlemann, G. 2012. The Ustilago maydis effector Pep1 suppresses plant immunity by inhibition of host peroxidase activity. PLoS Pathog. 8: e1002684.

Jamir, Y., Guo, M., Oh, H.-S., Petnicki-Ocwieja, T., Chen, S., Tang, X., Dickman, M. B., Collmer, A., and Alfano, J. R. 2004. Identification of Pseudomonas syringae type III effectors that can suppress programmed cell death in plants and yeast. Plant J. 37:554-565.

Jelenska, J., van Hal, J. A., and Greenberg, J. T. 2010. Pseudomonas syringae hijacks plant stress chaperone machinery for virulence. Proc. Natl. Acad. Sci. U.S.A. 107:13177-13182.

Jelenska, J., Yao, N., Vinatzer, B. A., Wright, C. M., Brodsky, J. L., and Greenberg, J. T. 2007. A J domain virulence effector of Pseudomonas syringae remodels host chloroplasts and suppresses defenses. Curr. Biol. 17:499-508.

Jones, J. D., and Dangl, J. L. 2006. The plant immune system. Nature 444: 323-329.

Kawai-Yamada, M., Ohori, Y., and Uchimiya, H. 2004. Dissection of Arabidopsis Bax inhibitor-1 suppressing Bax-, hydrogen peroxide-, and salicylic acid-induced cell death. Plant Cell 16:21-32.

Kelly, A. C., and Ward, T. J. 2018. Population genomics of Fusarium graminearum reveals signatures of divergent evolution within a major cereal pathogen. PLoS One 13:e0194616.

Kubicek, C. P., Starr, T. L., and Glass, N. L. 2014. Plant cell wall-degrading enzymes and their secretion in plant-pathogenic fungi. Annu. Rev. Phytopathol. 52:427-451.

Lacomme, C., and Santa Cruz, S. 1999. Bax-induced cell death in tobacco is similar to the hypersensitive response. Proc. Natl. Acad. Sci. U.S.A. 96:7956-7961.

Lee, T., Lee, S.-H., Shin, J. Y., Kim, H.-K., Yun, S.-H., Kim, H.-Y., Lee, S., and Ryu, J.-G. 2014. Comparison of trichothecene biosynthetic gene expression between Fusarium graminearum and Fusarium asiaticum. Plant Pathol. J. 30:33-42.

Liu, T., Liu, Z., Song, C., Hu, Y., Han, Z., She, J., Fan, F., Wang, J., Jin, C., Chang, J., Zhou, J. M., and Chai, J. 2012. Chitin-induced dimerization activates a plant immune receptor. Science 336:1160-1164.

Lo Presti, L., Lanver, D., Schweizer, G., Tanaka, S., Liang, L., Tollot, M., Zuccaro, A., Reissmann, S., and Kahmann, R. 2015. Fungal effectors and plant susceptibility. Annu. Rev. Plant Biol. 66:513-545.

Mackey, D., Belkhadir, Y., Alonso, J. M., Ecker, J. R., and Dangl, J. L. 2003. Arabidopsis RIN4 is a target of the type III virulence effector AvrRpt2 and modulates RPS2-mediated resistance. Cell 112:379-389.

Margolles-Clark, E., Tenkanen, M., Nakari-Setälä, T., and Penttilä, M. 1996. Cloning of genes encoding alpha-L-arabinofuranosidase and betaxylosidase from Trichoderma reesei by expression in Saccharomyces cerevisiae. Appl. Environ. Microbiol. 62:3840-3846. 
Melotto, M., Underwood, W., Koczan, J., Nomura, K., and He, S. Y. 2006. Plant stomata function in innate immunity against bacterial invasion. Cell 126:969-980.

Mullins, E. D., Chen, X., Romaine, P., Raina, R., Geiser, D. M., and Kang, S. 2001. Agrobacterium-mediated transformation of Fusarium oxysporum: An efficient tool for insertional mutagenesis and gene transfer. Phytopathology 91:173-180.

Nafisi, M., Stranne, M., Zhang, L., van Kan, J. A. L., and Sakuragi, Y. 2014. The endo-arabinanase BcAra1 is a novel host-specific virulence factor of the necrotic fungal phytopathogen Botrytis cinerea. Mol. Plant-Microbe Interact. 27:781-792.

Nakagawa, T., Kurose, T., Hino, T., Tanaka, K., Kawamukai, M., Niwa, Y., Toyooka, K., Matsuoka, K., Jinbo, T., and Kimura, T. 2007. Development of series of gateway binary vectors, pGWBs, for realizing efficient construction of fusion genes for plant transformation. J. Biosci. Bioeng. 104:34-41.

Nishiuchi, T., Masuda, D., Nakashita, H., Ichimura, K., Shinozaki, K., Yoshida, S., Kimura, M., Yamaguchi, I., and Yamaguchi, K. 2006. Fusarium phytotoxin trichothecenes have an elicitor-like activity in Arabidopsis thaliana, but the activity differed significantly among their molecular species. Mol. Plant-Microbe Interact. 19:512-520.

Paccanaro, M. C., Sella, L., Castiglioni, C., Giacomello, F., MartínezRocha, A. L., D’Ovidio, R., Schäfer, W., and Favaron, F. 2017. Synergistic effect of different plant cell wall-degrading enzymes is important for virulence of Fusarium graminearum. Mol. Plant-Microbe Interact. 30:886-895.

Paës, G., Skov, L. K., O’Donohue, M. J., Rémond, C., Kastrup, J. S., Gajhede, M., and Mirza, O. 2008. The structure of the complex between a branched pentasaccharide and Thermobacillus xylanilyticus GH-51 arabinofuranosidase reveals xylan-binding determinants and induced fit. Biochemistry 47:7441-7451.

Paper, J. M., Scott-Craig, J. S., Adhikari, N. D., Cuomo, C. A., and Walton, J. D. 2007. Comparative proteomics of extracellular proteins in vitro and in planta from the pathogenic fungus Fusarium graminearum. Proteomics 7:3171-3183.

Paz, Z., García-Pedrajas, M. D., Andrews, D. L., Klosterman, S. J., BaezaMontañez, L., and Gold, S. E. 2011. One step construction of Agrobacterium-recombination-ready-plasmids (OSCAR), an efficient and robust tool for ATMT based gene deletion construction in fungi. Fungal Genet. Biol. 48:677-684.

Proctor, R. H., Hohn, T. M., and McCormick, S. P. 1995. Reduced virulence of Gibberella zeae caused by disruption of a trichothecene toxin biosynthetic gene. Mol. Plant-Microbe Interact. 8:593-601.

Ramachandran, S. R., Yin, C., Kud, J., Tanaka, K., Mahoney, A. K., Xiao, F., and Hulbert, S. H. 2017. Effectors from wheat rust fungi suppress multiple plant defense responses. Phytopathology 107:75-83.

Rehnstrom, A. L., Free, S. J., and Pratt, R. G. 1994. Isolation, characterization and pathogenicity of Sclerotinia trifoliorum arabinofuranosidase-deficient mutants. Physiol. Mol. Plant Pathol. 44:199-206.

Rodríguez-Herva, J. J., González-Melendi, P., Cuartas-Lanza, R., AntúnezLamas, M., Río-Alvarez, I., Li, Z., López-Torrejón, G., Díaz, I., Del Pozo, J. C., Chakravarthy, S., Collmer, A., Rodríguez-Palenzuela, P., and López-Solanilla, E. 2012. A bacterial cysteine protease effector protein interferes with photosynthesis to suppress plant innate immune responses. Cell. Microbiol. 14:669-681.

Seiboth, B., and Metz, B. 2011. Fungal arabinan and L-arabinose metabolism. Appl. Microbiol. Biotechnol. 89:1665-1673.

Sella, L., Gazzetti, K., Faoro, F., Odorizzi, S., D’Ovidio, R., Schäfer, W., and Favaron, F. 2013. A Fusarium graminearum xylanase expressed during wheat infection is a necrotizing factor but is not essential for virulence. Plant Physiol. Biochem. 64:1-10.

Son, H., Seo, Y.-S., Min, K., Park, A. R., Lee, J., Jin, J. M., Lin, Y., Cao, P., Hong, S. Y., Kim, E. K., Lee, S. H., Cho, A., Lee, S., Kim, M. G., Kim, Y., Kim, J. E., Kim, J. C., Choi, G. J., Yun, S. H., Lim, J. Y., Kim, M., Lee, Y. H., Choi, Y. D., and Lee, Y. W. 2011. A phenome-based functional analysis of transcription factors in the cereal head blight fungus, Fusarium graminearum. PLoS Pathog. 7:e1002310.

Soong, G., Muir, A., Gomez, M. I., Waks, J., Reddy, B., Planet, P., Singh, P. K., Kaneko, Y., Wolfgang, M. C., Hsiao, Y. S., Tong, L., and Prince, A. 2006. Bacterial neuraminidase facilitates mucosal infection by participating in biofilm production. J. Clin. Invest. 116:2297-2305.

Torres, M. A., Jones, J. D. G., and Dangl, J. L. 2006. Reactive oxygen species signaling in response to pathogens. Plant Physiol. 141:373-378.

Voigt, C. A., Schäfer, W., and Salomon, S. 2005. A secreted lipase of Fusarium graminearum is a virulence factor required for infection of cereals. Plant J. 42:364-375.

Wang, C., Zhang, S., Hou, R., Zhao, Z., Zheng, Q., Xu, Q., Zheng, D., Wang, G., Liu, H., Gao, X., Ma, J. W., Kistler, H. C., Kang, Z., and Xu, J. R. 2011. Functional analysis of the kinome of the wheat scab fungus Fusarium graminearum. PLoS Pathog. 7:e1002460.

Wang, Q., Han, C., Ferreira, A. O., Yu, X., Ye, W., Tripathy, S., Kale, S. D., Gu, B., Sheng, Y., Sui, Y., Wang, X., Zhang, Z., Cheng, B., Dong, S., Shan, W., Zheng, X., Dou, D., Tyler, B. M., and Wang, Y. 2011. Transcriptional programming and functional interactions within the Phytophthora sojae RXLR effector repertoire. Plant Cell 23:2064-2086.

Zhang, X. W., Jia, L. J., Zhang, Y., Jiang, G., Li, X., Zhang, D., and Tang, W. H. 2012. In planta stage-specific fungal gene profiling elucidates the molecular strategies of Fusarium graminearum growing inside wheat coleoptiles. Plant Cell 24:5159-5176.

Zhang, Y. 2008. I-TASSER server for protein 3D structure prediction. BMC Bioinf. 9:40.

\section{AUTHOR-RECOMMENDED INTERNET RESOURCE}

CLC Genomics Workbench: https://www.qiagenbioinformatics.com/ 